\title{
SSTR-2 as a potential tumour-specific marker for fluorescence-guided meningioma surgery
}

\author{
B. M. Dijkstra ${ }^{1}$ - A. Motekallemi ${ }^{2}$ - W. F. A. den Dunnen ${ }^{3}$ - J. R. Jeltema ${ }^{1}$ • G. M. van Dam ${ }^{4}$ • F. A. E. Kruyt ${ }^{5}$. \\ R. J. M. Groen ${ }^{1}$
}

Received: 28 March 2018 / Accepted: 23 May 2018 / Published online: 1 June 2018

(C) The Author(s) 2018

\begin{abstract}
Background Meningiomas are the most frequently occurring primary intracranial tumours in adults. Surgical removal can only be curative by complete resection; however surgical access can be challenging due to anatomical localization and local invasion of bone and soft tissues. Several intraoperative techniques have been tried to improve surgical resection, including intraoperative fluorescence guided imaging; however, no meningioma-specific (fluorescent) targeting has been developed yet. Here, we aimed to identify the most promising biomarkers for targeted intra-operative fluorescence guided meningioma surgery.

Methods One hundred forty-eight meningioma specimens representing all meningioma grades were analysed using immunohistochemistry (IHC) on tissue microarrays (TMAs) to determine expression patterns of meningioma biomarkers epithelial membrane antigen (EMA), platelet-derived growth factor $\beta$ (PDGF- $\beta$ ), vascular endothelial growth factor $\alpha$ (VEGF- $\alpha$ ), and somatostatin receptor type 2 (SSTR-2). Subsequently, the most promising biomarker was selected based on TArget Selection Criteria (TASC). Marker expression was examined by IHC in 3D cell culture models generated from freshly resected tumour material.

Results TMA-IHC showed strongest staining for SSTR-2. All cases were positive, with 51.4\% strong/diffuse, 30.4\% moderate/diffuse and only $18.2 \%$ focal/weak staining patterns. All tested biomarkers showed at least weak positivity in all meningiomas, regardless of WHO grade. TASC analysis showed that SSTR-2 was the most promising target for fluorescence guided imaging, with a total score of 21 (out of 22). SSTR-2 expression was determined on original patient tumours and 3D cultures of three established cultures.

Conclusions SSTR-2 expression was highly sensitive and specific in all 148 meningiomas, regardless of WHO grade. According to TASC analysis, SSTR-2 is the most promising receptor for meningioma targeting. After establishing in vitro meningioma models, SSTR-2 cell membrane expression was confirmed in two of three meningioma cultures as well. This indicates that specific fluorescence in an experimental setting can be performed for the further development of targeted fluorescence guided

B. M. Dijkstra and A. Motekallemi contributed equally to this work.

R. J. M. Groen

r.j.m.groen@umcg.nl

1 Department of Neurosurgery, University Medical Center Groningen, University of Groningen, Hanzeplein 1, P.O. Box 30.001, 9700 RB Groningen, The Netherlands

2 Department of Neurosurgery, University Medical Center Münster, Münster, Germany

3 Department of Pathology, University Medical Center Groningen, University of Groningen, Groningen, The Netherlands

4 Department of Surgery, Nuclear Medicine and Molecular Imaging and Intensive Care, University Medical Center Groningen, University of Groningen, Groningen, The Netherlands

5 Department of Medical Oncology, University Medical Center Groningen, University of Groningen, Groningen, The Netherlands

meningioma surgery and near-infrared fluorescent tracers targeting SSTR-2.

Keywords Intracranial meningioma - Fluorescence guided surgery - Intraoperative imaging - Somatostatin receptor subtype $2 \cdot$ Biomarker

\begin{tabular}{ll}
\multicolumn{2}{l}{ Abbreviations } \\
EMA & Epithelial membrane antigen \\
IHC & Immunohistochemistry \\
PDGFR- $\beta$ & Platelet-derived growth factor receptor beta \\
SSTR-2 & Somatostatin receptor type 2 \\
T/N & Tumour-to-normal tissue ratio \\
TASC & TArget Selection Criteria \\
TMA & Tissue microarray \\
VEGF- $\alpha$ & Vascular endothelial growth factor A
\end{tabular}
\end{abstract}




\section{Introduction}

Meningiomas are the most frequently occurring intracranial tumours in adults, accounting for approximately one third of cases [37]. They are classified by the World Health Organization (WHO) into three malignancy grades with 15 histologic subtypes [26]. Treatment is usually only curative with complete surgical resection $[6,50]$ and aims for both complete tumour removal and preservation of neurological function $[29,55]$. Although mostly benign and slow growing, all meningiomas can pose surgical challenges due to anatomical localization and local invasion of bone and soft tissues, leading to residual tumour tissue. Incomplete resection is one of the risk factors for recurrence [6].

One of the proposed techniques to facilitate resection is intraoperative fluorescence-guided imaging. Several fluorescent dyes (5-aminolevulinic acid, fluorescein, and indocyanine green) have been tried $[1,10,14,25,33]$; however, evidence regarding the benefit of applying these dyes is unavailable. Furthermore, fluorescent dyes currently lack specificity. The concept of targeted fluorescence is appealing, due to high sensitivity and specificity rates. Identification of meningioma-specific biomarkers is a first and essential step in this concept. Comparable targeted fluorescent techniques have been established in other tumour types, e.g. in ovarian carcinoma $[17,53]$ and peritoneal metastases of colorectal carcinomas [18] targeting $\alpha \mathrm{v} \beta 3$-integrin or folate receptor $\alpha$ and VEGF- $\alpha$, respectively. For the development of a similar approach in meningioma surgery, various biomarkers have been suggested, including epithelial membrane antigen (EMA), platelet-derived growth factor beta (PDGF- $\beta$ ), vascular endothelial growth factor A (VEGF- $\alpha$ ), and somatostatin receptor type 2 (SSTR-2) [3, 5, 9, 11, 12, 16, 19, 21, 28, 30, 32, 38, 39, 43-45, $48,52,56]$. However, the suitability of these markers for fluorescence-guided imaging meningioma surgery has not yet been investigated.

In this study, we aimed to make a step-wise approach: (1) identifying meningioma-specific candidate biomarkers (EMA, PDGF- $\beta$, VEGF- $\alpha$ and SSTR-2); (2) selecting the most promising tumour-specific marker; and (3) confirming its expression in in vitro cultures derived from fresh meningioma specimens.

\section{Methods and materials}

\section{Part 1: identifying meningioma-specific candidate biomarkers}

Specimens of previously untreated, primary intracranial meningiomas resected between January 2006 and December 2010 were retrospectively analysed for the expression of four potential biomarkers (i.e. EMA, PDGF- $\beta$, VEGF- $\alpha$ and SSTR-2). A total number of 148 meningioma specimens were available for analysis. All patient data were anonymized according to the regulations of the Medical Ethical Research Committee of the University Medical Center Groningen.

Meningioma samples were examined using tissue microarrays (TMAs). TMA sections were deparaffinised with xylene, rehydrated in ethanol, and rinsed in distilled water. After antigen retrieval with a Tris-EDTA or Tris-HCl buffer, endogenous peroxidase was blocked for 30 min using a $0.1 \% \mathrm{H}_{2} \mathrm{O}_{2}$ PBS solution. Respective antibody staining was performed at room temperature. The selected primary antibodies of interest were anti-EMA (mouse monoclonal, Dako), anti-PDGFR- $\beta$ (rabbit polyclonal, Santa Cruz), anti-VEGF- $\alpha$ (rabbit polyclonal, Santa Cruz) and anti-SSTR-2 (rabbit monoclonal, Epitomics). We used normal cerebellar and anterior pituitary tissue as positive controls. Additionally, we omitted the primary antibody and used IgG controls. Secondary and tertiary antibody staining was performed for $30 \mathrm{~min}$. All sections were subjected to a 3,3diaminobenzidine solution for $10 \mathrm{~min}$ and finally counterstained with haematoxylin for $2 \mathrm{~min}$, dehydrated in ethanol, cleared, mounted and cover slipped.

For immunohistochemical (IHC) evaluation, TMA sections were scanned with an ultra-resolution digital scanner ScanScope CS $\AA$, Aperio ${ }^{\circledR}$ with $\times 20$ image magnification and evaluated with Aperio ImageScope ${ }^{\circledR}$ software. Each tissue core of the TMA section was scored using the following scoring method: negative, (0); weak/focal staining, (1); moderate/ diffuse staining, (2); strong/diffuse staining, (3). Two authors (AM and WFD) independently evaluated tissue cores and in case of discrepant scores, consensus was reached by way of discussion between both evaluators. Cores were regarded as non-informative and consequently dismissed when $>50 \%$ tissue was lost or presented inappropriate amounts of collagen staining. Tumour specimens which were represented by less than two complete cores were excluded. A mean score was calculated for each specimen and specimens with an average score of 1 were considered positive, whereas specimens with a mean score of $\geq 2$ were summarized as "high score".

\section{Statistical analysis}

All statistical analyses were performed using IBM $®$ SPSS $®$ Statistics 20. Spearman rank-order correlation was used to find correlation between targets and WHO classifications. All reported $P$ values were two sided and a value of $P \leq 0.05$ was considered as statistically significant.

\section{Part 2: selecting the most promising tumour-specific marker}

To investigate the usefulness of these markers for intraoperative fluorescence-guided imaging, the TArget Selection Criteria (TASC) [54] were utilized for the selection of the most promising targets, as depicted in Table 1. 
Table 1 TASC scoring system

\begin{tabular}{llll}
\hline Criteria & Characteristics & & Score \\
\hline I & Extracellular protein localization & Bound to cell surface (receptor) & 5 \\
& & In close proximity of tumour cell & 3 \\
II & Diffuse upregulation through tumour & & 4 \\
tissue & & 3 \\
III & Tumour-to-normal ratio $>10$ & & 6 \\
IV & Percentage upregulation in patients & $>90 \%$ & 5 \\
& & $70-89 \%$ & 3 \\
& & $50-69 \%$ & 0 \\
V & & $10-49 \%$ & 2 \\
VI & & & 1 \\
VII & Previously successfully imaged in vivo & & 1 \\
Maximum: 22 & Enzymatic activity & & \\
Potential target & Internalization & & \\
$\quad \geq 18$ & & & \\
\hline
\end{tabular}

\section{Part 3: confirming expression in in vitro cultures}

Meningioma 3D cell culture models were established to provide an accurate model for the disease [13, 24]. Surgical leftover fresh tumour tissue was washed with ice-cold PBS and mechanically dissociated. After adding 15 to $20 \mathrm{ml}$ accutase, tissue incubated for $30 \mathrm{~min}$ at room temperature. The suspension was passed through a $70-\mu \mathrm{m}$ cell strainer to procure single cells and pelleted. Cells were seeded in T75 flasks with medium containing DMEM/F12 supplemented with $2 \%$ B27, $20 \mathrm{ng} / \mathrm{ml} \mathrm{EGF,} 20 \mathrm{ng} / \mathrm{ml} \mathrm{bFGF} \mathrm{[22],} \mathrm{and} \mathrm{2 \%} \mathrm{pen/strep.}$

For IHC analyses, 3D cultures were dissociated with accutase and cytospun. Subsequently, cells were fixated with $4 \%$ formaldehyde, washed with PBS and underwent a blocking step with $1 \% \mathrm{H}_{2} \mathrm{O}_{2}$ in PBS for $10 \mathrm{~min}$. Cells were then incubated with anti-SSTR-2 (1:100; MAB4224, R\&D systems) for $1 \mathrm{~h}$, followed by incubation of the corresponding secondary and tertiary antibodies diluted at 1:50 in PBS with $1 \% \mathrm{BSA}$ and $1 \% \mathrm{AB}$ serum for $30 \mathrm{~min}$. Lastly, cells were incubated with 5\% 3-amino-9-ethylcarbazole diluted in acetate buffer with $0.1 \%$ hydrogen peroxide for $10 \mathrm{~min}$, counterstained with haematoxylin for $2 \mathrm{~min}$, and mounted with

Table 2 Patient and tumour specimen characteristics

\begin{tabular}{lll}
\hline & Men & Women \\
\hline Percent $(n(\%))$ & $52(35.1)$ & $96(64.9)$ \\
Age (years) (mean (range)) & $47.2(4.4-79.8)$ & $52.4(4.2-77.5)$ \\
Meningioma grade $(n(\% *))$ & & \\
WHO I & $38(25.7)$ & $86(58.1)$ \\
WHO II & $12(8.1)$ & $10(6.8)$ \\
WHO III & $2(1.4)$ & $0(0.0)$ \\
\hline
\end{tabular}

*Percentage of all meningiomas
Kaiser's glycerin for microscopic examination using a Leica DM 3000 microscope.

\section{Results}

\section{Part 1: identifying meningioma-specific candidate biomarkers}

\section{Patient characteristics}

Patient and tumour characteristics are summarized in Table 2. The age at surgery ranged from 4 to 79 years. Tumour specimens were obtained from 52 male and 96 female patients. Our study revealed 124 WHO I (83.8\%), 22 WHO II (14.9\%) and 2 WHO III (1.4\%) meningiomas. All tested biomarkers showed at least weak positivity in all meningiomas, regardless of WHO grade. No association was found between WHO grade and the expression rates of the potential targets using Spearman rank order correlation (Table 3).

Table 3 Correlation between target expression and WHO grades

\begin{tabular}{lc}
\hline Target & Spearman correlation $(p$ value $)$ \\
\hline EMA & .498 \\
VEGF- $\alpha$ & .909 \\
PDGFR- $\beta$ & .255 \\
SSTR-2 & .647 \\
\hline
\end{tabular}


Table 4 Summary of IHC results

\begin{tabular}{llllll}
\hline Target & $\begin{array}{l}\text { Valid } \\
\text { cores }\end{array}$ & $\begin{array}{l}\text { Weak/focal } \\
(\%)\end{array}$ & $\begin{array}{l}\text { Moderate/ diffuse } \\
(\%)\end{array}$ & $\begin{array}{l}\text { Strong/diffuse } \\
(\%)\end{array}$ & High score* (\%) \\
\hline EMA & 148 & $16(10.8)$ & $113(76.4)$ & $19(12.8)$ & $132(89.2)$ \\
VEGF- $\alpha$ & 145 & $45(31.0)$ & $93(64.1)$ & $7(4.8)$ & $100(69.0)$ \\
PDGFR- $\beta$ & 147 & $34(23.1)$ & $107(72.8)$ & $6(4.1)$ & $113(76.9)$ \\
SSTR-2 & 148 & $27(18.2)$ & $45(30.4)$ & $76(51.4)$ & $121(81.8)$ \\
\hline
\end{tabular}

Shown percentages are valid ratios for the respective target

*Defined as moderate/diffuse or strong/diffuse staining

\section{Target expression in TMA sections}

Both cerebellar and anterior pituitary tissue showed SSTR-2positivity. Additionally, white matter in the cerebellar tissue was SSTR-2 negative, as expected. Omission of the primary antibody revealed no SSTR-2 staining and aspecific binding with IgG was not observed.

TMA-IHC results are summarized in Table 4. Of all TMA meningioma specimens (588), 99.8\% was IHC-positive for the investigated targets with at least two or more valid tissue cores. The number of non-informative/invalid cores was low for PDGFR- $\beta$ (0.7\%) and VEGF- $\alpha$ (2.0\%) and all cores for EMA and SSTR-2 were valid. The IHC staining score for SSTR-2 was the most robust, resulting in positivity for SSTR-2 in all specimen: moderate/diffuse or strong/diffuse positivity in $81.8 \%$ ("high score") and focal/weak positivity in only $18.2 \%$ of all cases. Representative examples illustrating SSTR-2 expression are shown in Fig. 1.

\section{Part 2: selecting the most promising tumour-specific marker}

The selected markers were evaluated using TASC based on IHC-TMA results (Table 5). Using these criteria, SSTR-2 is the most promising target for intra-operative use with a total TASC score of 21. In addition, EMA, PDGFR- $\beta$ and
VEGF- $\alpha$ seem to be high potential targets with TASC scores of 20,20 and 18 , respectively.

\section{Part 3: confirming expression in in vitro cultures}

\section{Generating meningioma cultures}

In vitro cultures were established to further explore the potential of SSTR-2 as a meningioma-specific marker in a translational model. After processing the freshly resected material, 11 of 22 cultures $(50 \%)$ generated 3D cultures after 7 days (Fig. 2, top panel). However, growth decreased after three to four passages. A selection of three cultures named $\mathrm{MgG}_{24}$, MgG26 and MgG27 was characterized in more detail. These cultures originated from three female patients with a mean age of 65.7 years (range 60-77; SD 9.8). All meningiomas were WHO grade I, with one transitional and two meningothelial meningiomas (Fig. 2, middle panel). Two meningiomas were located at the convexity and one at the skull base (Fig. 2, bottom panel).

\section{SSTR-2 expression in in vitro meningioma cultures}

SSTR-2 expression was determined on original patient tumours and 3D cultures of the three established cultures. All patient tumours were strongly positive for SSTR-2 at the cell
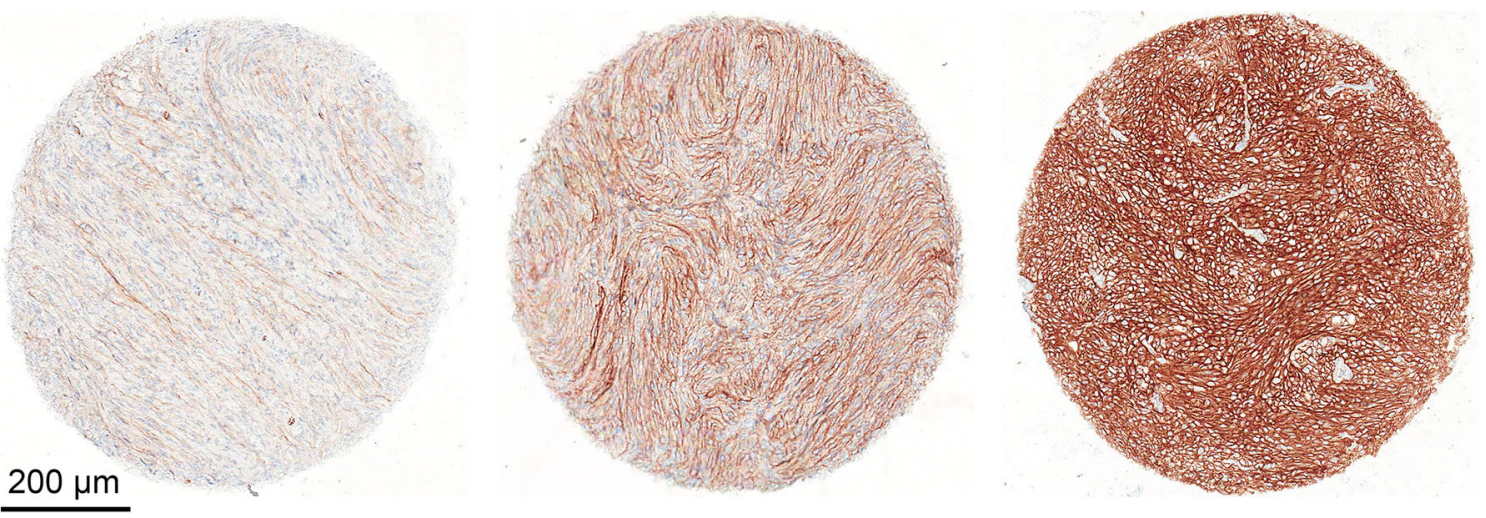

Fig. 1 Representative images of SSTR-2 stained TMA-IHC cores and scoring approach. Shown are weak/focal (left), moderate/diffuse (middle), and strong/diffuse (right) staining patterns 
Table 5 Target selection by applying TASC

\begin{tabular}{llllllll}
\hline $\begin{array}{l}\text { TASC } \\
\text { item } \\
\text { Target }\end{array}$ & Localization & $\begin{array}{l}\text { II } \\
\text { Expression } \\
\text { pattern* } *\end{array}$ & $\begin{array}{l}\text { III } \\
\text { T/N } \\
\text { ratio }\end{array}$ & $\begin{array}{l}\text { IV } \\
\text { Upregulation } \\
\text { in patients* } \\
(\%)\end{array}$ & $\begin{array}{l}\text { V } \\
\text { In vivo } \\
\text { imaging }\end{array}$ & $\begin{array}{l}\text { VI } \\
\text { Enzymatic } \\
\text { activity }\end{array}$ & $\begin{array}{l}\text { VII } \\
\text { Internalization }\end{array}$ \\
\hline EMA & Transmembrane & Diffuse & High & 100 & Yes [34, 49] & ND & ND \\
VEGF- $\alpha$ & Secreted & Diffuse & High & 100 & Yes [35,36,47] & ND & ND \\
PDGFR- $\beta$ & Transmembrane & Diffuse & High & 100 & Yes [15] & ND & ND \\
SSTR-2 & Transmembrane & Diffuse & High & 100 & Yes [21,23,52] & Yes [46] & ND \\
\hline
\end{tabular}

$N D$, not described; $T / N$ ratio, tumour-to-normal tissue ratio

*Results based on this study

"Expression patterns are considered "diffuse", if moderate/diffuse or strong/diffuse staining is present in more than $66 \%$ of included cases

membrane (Fig. 3, top panel). However, of the dissociated 3D cultures, only MgG24 and MgG26 are SSTR-2 positive with a cell membranous staining. It should be noted that not all cells are (equally) positive in both cultures: some cells show no or weak SSTR-2 positivity, whereas in other cells, the staining is strongly positive (Fig. 3, bottom panel).
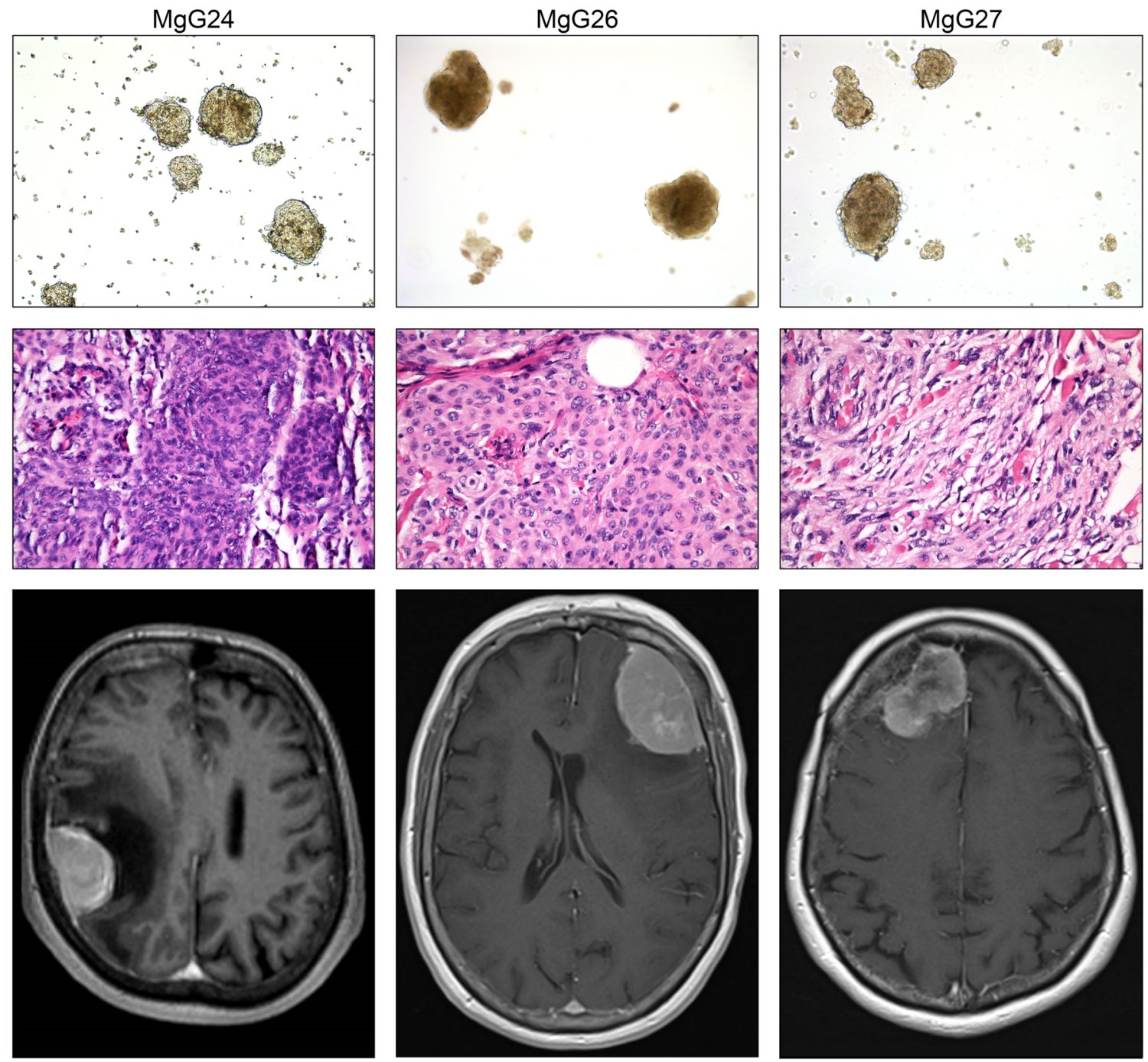

Fig. 2 Top panel shows micrographs of 3D meningioma cultures with $\times$ 10 magnification. Middle panel depicts micrographs of H\&E stained original patient tumour at $\times 40$ magnification. Bottom panel are gadolinium-enhanced MRI scans. 3D cultures showed aggregated cell formation into a sphere. H\&E stained tumour samples confirmed the diagnosis of meningioma in all three cases. MRI scans revealed meningiomas at the convexity and skull base 

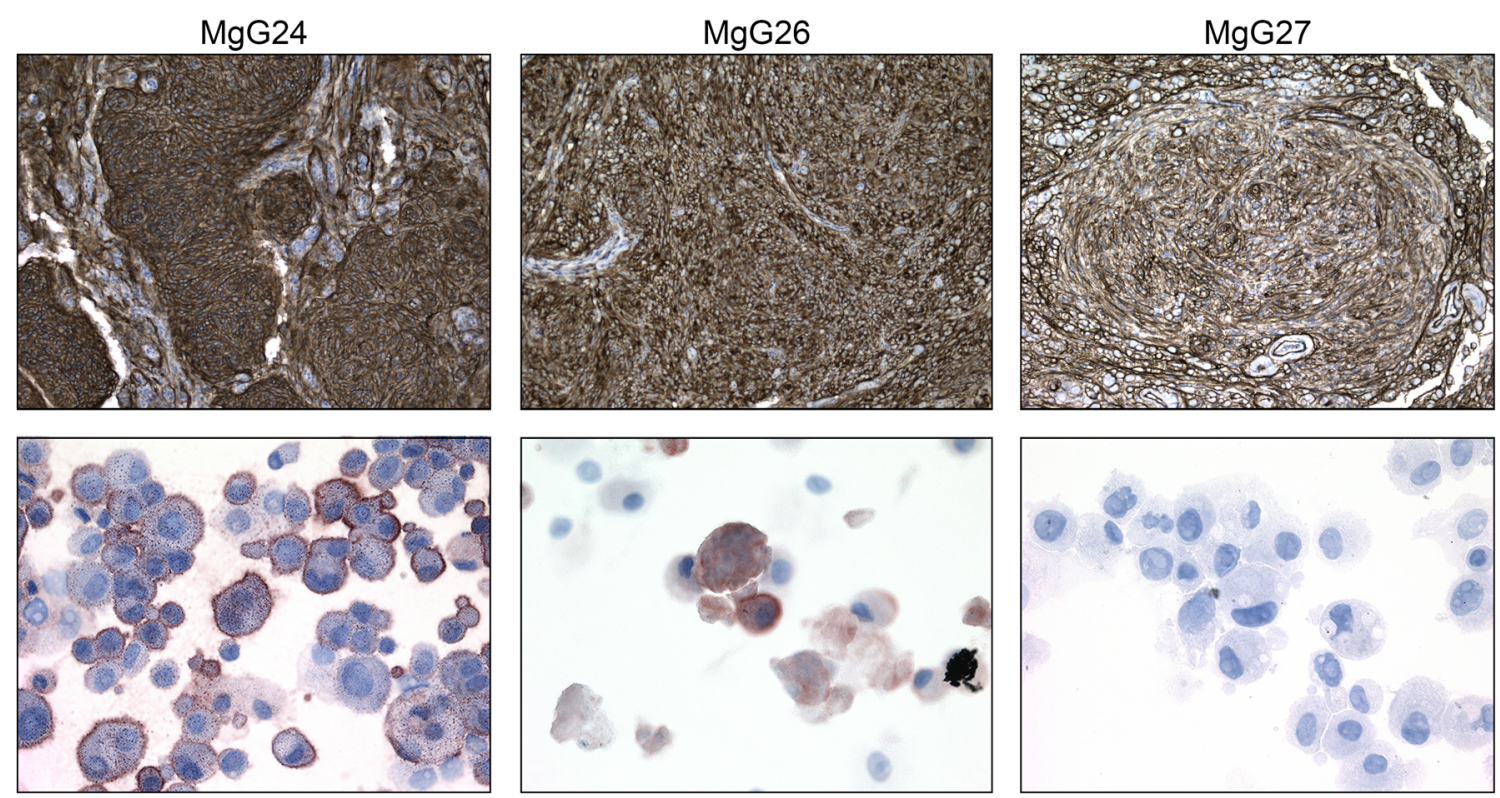

Fig. 3 Top panel depicts micrographs from primary tumour stained for SSTR2 at $\times 10$ magnification. Bottom panel shows micrographs of dissociated cells cultured as $3 \mathrm{D}$ and stained for SSTR 2 at $\times 40$

magnification. Patient material showed SSTR-2 membrane staining in all tumours. Two of three dissociated 3D cultures revealed SSTR-2 positive membranous staining in a fraction of cells

\section{Discussion}

The first aim of this study was to identify the expression pattern of a series of preselected markers (EMA, PDGF- $\beta$, VEGF- $\alpha$ and SSTR-2) in meningiomas using TMA-IHC, which resulted in the analysis of a large collection of tested meningioma samples. We confirmed previous findings regarding meningioma biomarkers $[3,5,9,11,12,16,19,21$, $28,30,32,38,39,43-45,48,52,56]$. All investigated markers tested positive in all meningiomas, regardless of WHO grade. However, SSTR-2 expression was especially robust with a "high score" in $81.8 \%$ of all cases. SSTR-2 was also highly specific and sensitive. These findings are in line with previous studies [12, 30, 48]. Subsequently we focused on the second aim of this study, namely, identifying the most promising tumour-specific marker for intraoperative application. Applying TASC, SSTR-2 was found to be superior when compared to the other three biomarkers. Although TASC was initially developed for target selection in colorectal cancer and has not yet been validated in other tumours, the principle is also applicable to other tumour types as it is based on biomarker characteristics and not on a specific tumour type. This tool (TASC) is the first structured method to determine the suitability of a biomarker for intraoperative imaging. As a major advantage, TASC provides an objective score by considering available evidence.

The potential of SSTR-2 was analysed in a translational model using newly generated patient-derived 3D meningioma cultures. In two of three tested cultures, SSTR-2 expression was present at the cell membrane, emphasizing the possibility of SSTR-2 as a potential target for fluorescence guided

imaging. One culture was SSTR-2 negative, which may be due to a technical issue with reduced culture viability. Indeed, the original patient tumour was SSTR-2 positive. Further research is warranted to investigate this issue further. As far as we know, this is the first time that the expression SSTR-2 has been determined in in vitro meningioma cultures using IHC. Several limitations became apparent when using this model. The cultures could be subcultured for a limited number of passages: cell growth decreased after three to four passages, similar to a previous report [51]. Moreover, the generated in vitro models are all originating from WHO grade I meningiomas. Although patients with high grade lesions may benefit the most from intraoperative imaging, WHO I meningiomas are still a representable model as SSTR-2 is expressed in all meningiomas, regardless the grade $[30,48]$.

The present study is an essential first step towards the development of meningioma-specific intraoperative fluorescenceguided imaging. Future steps should consist of binding studies with fluorescent dyes (preferably near-infrared dyes, such as IRDye $800 \mathrm{CW}$ ) with SSTR-2 analogues (e.g. octreotate). These have already been used in targeted therapy for recurrent meningiomas $[2,8,42]$ and their application in theranostics and PET-scanning has been demonstrated [19, 21, 52]. IRDye 800 CW has undergone a microdosing study [27] and has been applied in various clinical trials [57]. Further validation is needed by testing a target-directed imaging tool in vitro for proof of concept, and subsequently in in vivo animal models using xenograft mouse models. Animal models have been successfully applied previously, using fresh patient-derived material [20,31, $41,51]$ or immortalized meningioma cell lines [4, 7, 40, 41], with higher grade meningiomas yielding a higher success rate. 
Such models are needed for translational research to assess SSTR-2 guided intra-operative meningioma surgery.

\section{Conclusions}

The present results highlight the potential of SSTR-2 as a high potential target for fluorescence-guided imaging. We identified SSTR-2 as the most suitable biomarker for targeted fluorescence-guided meningioma surgery by applying TMAIHC and TASC. SSTR-2 was highly sensitive and specific and was expressed in all meningiomas in our large patient sample cohort, regardless of WHO grade. Furthermore, we established freshly generated in vitro meningioma models closely reflecting the original patient tumour and confirmed SSTR-2 expression in three meningioma cultures, which marks the first and essential step towards future in vitro experiments (tumour-cell imaging with fluorescently labelled SSTR-2 receptor markers) and in vivo experiments (meningioma identification in a mouse model). Further preclinical studies need to be performed to further develop the concept for targeted fluorescence-guided meningioma surgery.

\section{Compliance with ethical standards}

Conflict of interest The authors declare that they have no conflict of interest.

Ethical approval For this type of study formal consent is not required.

Animal experiments This article does not contain any studies with human participants or animals performed by any of the authors.

Open Access This article is distributed under the terms of the Creative Commons Attribution 4.0 International License (http:// creativecommons.org/licenses/by/4.0/), which permits unrestricted use, distribution, and reproduction in any medium, provided you give appropriate credit to the original author(s) and the source, provide a link to the Creative Commons license, and indicate if changes were made.

\section{References}

1. Akçakaya MO, Göker B, Kasımcan MÖ, Hamamcıoğlu MK, Kırıș $\mathrm{T}$ (2017) Use of sodium fluorescein in meningioma surgery performed under the YELLOW-560 nm surgical microscope filter: feasibility and preliminary results. World Neurosurg S18788750(17):31203-31202

2. Albers AR, O'Dorisio MS (1996) Clinical use of somatostatin analogues in paediatric oncology. Digestion 57(Suppl 1):38-41

3. Andrae N, Kirches E, Hartig R, Haase D, Keilhoff G, Kalinski T, Mawrin C (2012) Sunitinib targets PDGF-receptor and Flt3 and reduces survival and migration of human meningioma cells. Eur $\mathrm{J}$ Cancer 48(12):1831-1841

4. Baia G, Slocum A, Hyer J, Misra A, Sehati N, VandenBerg S, Feuerstein B, Deen D, McDermott M, Lal A (2006) A genetic strategy to overcome the senescence of primary meningioma cell cultures. J Neuro-Oncol 78(2):113-121

5. Barresi V (2011) Angiogenesis in meningiomas. Brain Tumor Pathol 28(2):99-106

6. Campbell BA, Jhamb A, Maguire JA, Toyota B, Ma R (2009) Meningiomas in 2009: controversies and future challenges. Am J Clin Oncol 32(1):73-85

7. Cargioli TG, Ugur HC, Ramakrishna N, Chan J, Black PM, Carroll RS (2007) Establishment of an in vivo meningioma model with human telomerase reverse transcriptase. Neurosurgery 60(4):750 760

8. Collamati F, Pepe A, Bellini F et al (2015) Toward radioguided surgery with $\beta$-decays: uptake of a somatostatin analogue, DOTATOC, in meningioma and high-grade glioma. J Nucl Med 56(1):3-8

9. Commins DL, Atkinson RD, Burnett ME (2007) Review of meningioma histopathology. Neurosurg Focus 23(4):E3

10. Da Silva CE, Duval V, da Silva CE, Braga JL, da Silva VD, da Silva JLB (2014) Skull Base Meningiomas and cranial nerves contrast using sodium fluorescein: a new application of an old tool. J Neurol Surg B Skull Base 75(4):255-260

11. De Menis E, Tulipano G, Villa S, Billeci D, Bonfanti C, Pollara P, Pauletto P, Giustina A (2003) Development of a meningioma in a patient with acromegaly during octreotide treatment: are there any causal relationships? J Endocrinol Investig 26(4):359-363

12. Dutour A, Kumar U, Panetta R, Ouafik L, Fina F, Sasi R, Patel YC (1998) Expression of somatostatin receptor subtypes in human brain tumors. Int J Cancer 76(5):620-627

13. Edmondson R, Broglie JJ, Adcock AF, Yang L (2014) Threedimensional cell culture systems and their applications in drug discovery and cell-based biosensors. Assay Drug Dev Technol 12(4): 207-218

14. Foster N, Eljamel S (2016) ALA-induced fluorescence image guided surgery of meningiomas: a meta-analyses. Photodiagn Photodyn Ther 15:73-78

15. Glekas AP, Pillarsetty NK, Punzalan B, Khan N, Smith-Jones P, Larson SM (2011) In vivo imaging of Bcr-Abl overexpressing tumors with a radiolabeled imatinib analog as an imaging surrogate for imatinib. J Nucl Med 52(8):1301-1307

16. Hanft S, Canoll P, Bruce JN (2010) A review of malignant meningiomas: diagnosis, characteristics, and treatment. J Neuro-Oncol 99(3):433-443

17. Harlaar NJ, Kelder W, Sarantopoulos A, Bart J, Themelis G, van Dam GM, Ntziachristos V (2013) Real-time near infrared fluorescence (NIRF) intra-operative imaging in ovarian cancer using an Qv 33 -integrin targeted agent. Gynecol Oncol 128(3):590-595

18. Harlaar NJ, Koller M, de Jongh SJ et al (2016) Molecular fluorescence-guided surgery of peritoneal carcinomatosis of colorectal origin: a single-centre feasibility study. Lancet Gastroenterol Hepatol 1(4):283-290

19. Henze M, Schuhmacher J, Hipp P, Kowalski J, Becker DW, Doll J, Mäcke HR, Hofman MS, Debus J, Haberkorn U (2001) PET imaging of somatostatin receptors using [68GA]DOTA-D-Phe1-Tyr3octreotide: first results in patients with meningiomas. J Nucl Med 42(7):1053-1056

20. Hueng D-Y, Sytwu H-K, Huang S-M, Chang C, Ma H-I (2011) Isolation and characterization of tumor stem-like cells from human meningiomas. J Neuro-Oncol 104(1):45-53

21. Hurst RD, Modlin IM (1993) Use of radiolabeled somatostatin analogs in the identification and treatment of somatostatin receptor-bearing tumors. Digestion 54(Suppl 1):88-91

22. Joseph JV, Conroy S, Tomar T et al (2014) TGF- $\beta$ is an inducer of ZEB1-dependent mesenchymal transdifferentiation in glioblastoma that is associated with tumor invasion. Cell Death Dis 5:e1443

23. Körner M, Waser B, Schonbrunn A, Perren A, Reubi JC (2012) Somatostatin receptor subtype $2 \mathrm{~A}$ immunohistochemistry using a 
new monoclonal antibody selects tumors suitable for in vivo somatostatin receptor targeting. Am J Surg Pathol 36(2):242-252

24. Lee J, Kotliarova S, Kotliarov Y et al (2006) Tumor stem cells derived from glioblastomas cultured in bFGF and EGF more closely mirror the phenotype and genotype of primary tumors than do serum-cultured cell lines. Cancer Cell 9(5):391-403

25. Lee JYK, Pierce JT, Thawani JP, Zeh R, Nie S, Martinez-Lage M, Singhal S (2017) Near-infrared fluorescent image-guided surgery for intracranial meningioma. J Neurosurg:1-11

26. Louis DN, Perry A, Reifenberger G, von Deimling A, FigarellaBranger D, Cavenee WK, Ohgaki H, Wiestler OD, Kleihues P, Ellison DW (2016) The 2016 World Health Organization classification of tumors of the central nervous system: a summary. Acta Neuropathol 131(6):803-820

27. Marshall MV, Draney D, Sevick-Muraca EM, Olive DM (2010) Single-dose intravenous toxicity study of IRDye $800 \mathrm{CW}$ in Sprague-Dawley rats. Mol Imaging Biol 12(6):583-594

28. Mauro A, Di Sapio A, Mocellini C, Schiffer D (1995) Control of meningioma cell growth by platelet-derived growth factor (PDGF). J Neurol Sci 131(2):135-143

29. McMullen KP, Stieber VW (2004) Meningioma: current treatment options and future directions. Curr Treat Options in Oncol 5(6): 499-509

30. Menke JR, Raleigh DR, Gown AM, Thomas S, Perry A, Tihan T (2015) Somatostatin receptor 2a is a more sensitive diagnostic marker of meningioma than epithelial membrane antigen. Acta Neuropathol 130(3):441-443

31. Michelhaugh SK, Guastella AR, Varadarajan K et al (2015) Development of patient-derived xenograft models from a spontaneously immortal low-grade meningioma cell line, KCI-MENG1. J Health Serv Res Policy 16(1):62-64

32. Miller R, DeCandio ML, Dixon-Mah Y, Giglio P, Vandergrift WA, Banik NL, Patel SJ, Varma AK, Das A (2014) Molecular targets and treatment of meningioma. J Neurol Neurosurg 1(1):1000101

33. Motekallemi A, Jeltema H-R, Metzemaekers JDM, van Dam GM, Crane LMA, Groen RJM (2015) The current status of 5-ALA fluorescence-guided resection of intracranial meningiomas - a critical review. Neurosurg Rev 38(4):619-628

34. Muguruma N, Ito S (2008) Labeled anti-mucin antibody detectable by infrared-fluorescence endoscopy. Cancer Biomark 4(6):321-328

35. Nagengast WB, Hooge MNL, van Straten EME et al (2011) VEGFSPECT with ${ }^{111}$ In-bevacizumab in stage III/IV melanoma patients. Eur J Cancer 47(10):1595-1602

36. Nagengast WB, de Vries EGE, Hospers GAP, Mulder NH, de Jong JR, Hollema H, Brouwers AH, van Dongen GA, Perk LR, Lub-de Hooge MN (2007) In vivo VEGF imaging with radiolabeled bevacizumab in a human ovarian tumor xenograft. J Nucl Med 48(8):1313-1319

37. Ostrom QT, Gittleman H, Fulop J, Liu M, Blanda R, Kromer C, Wolinsky Y, Kruchko C, Barnholtz-Sloan JS (2015) CBTRUS statistical report: primary brain and central nervous system tumors diagnosed in the United States in 2008-2012. Neuro-Oncology 17(Suppl 4):iv62

38. Panagopoulos AT, Lancellotti CLP, Veiga JCE, de Aguiar PHP, Colquhoun A (2008) Expression of cell adhesion proteins and proteins related to angiogenesis and fatty acid metabolism in benign, atypical, and anaplastic meningiomas. J Neuro-Oncol 89(1):73-87

39. Pfister C, Pfrommer H, Tatagiba MS, Roser F (2012) Vascular endothelial growth factor signals through platelet-derived growth factor receptor $\beta$ in meningiomas in vitro. Br J Cancer 107(10): $1702-1713$
40. Püttmann S, Senner V, Braune S, Hillmann B, Exeler R, Rickert $\mathrm{CH}$, Paulus W (2005) Establishment of a benign meningioma cell line by hTERT-mediated immortalization. Lab Investig 85(9): $1163-1171$

41. Ragel BT, Couldwell WT, Gillespie DL, Wendl MM, Whang K, Jensen RL (2008) A comparison of the cell lines used in meningioma research. Surg Neurol 70(3):295-307

42. Rammo R, Rock A, Transou A, Raghunathan A, Rock J (2016) Anaplastic meningioma: octreotide therapy for a case of recurrent and progressive intracranial disease. J Neurosurg 124(2):496-500

43. Reubi JC, Laissue JA (1995) Multiple actions of somatostatin in neoplastic disease. Trends Pharmacol Sci 16(3):110-115

44. Reubi JC, Maurer R, Klijn JG, Stefanko SZ, Foekens JA, Blaauw G, Blankenstein MA, Lamberts SWJ (1986) High incidence of somatostatin receptors in human meningiomas: biochemical characterization. J Clin Endocrinol Metab 63(2):433-438

45. Reubi JC, Schaer JC, Waser B, Mengod G (1994) Expression and localization of somatostatin receptor SSTR1, SSTR2, and SSTR3 messenger RNAs in primary human tumors using in situ hybridization. Cancer Res 54(13):3455-3459

46. Rinne P, Hellberg S, Kiugel M et al (2016) Comparison of somatostatin receptor 2-targeting PET tracers in the detection of mouse atherosclerotic plaques. Mol Imaging Biol 18(1):99-108

47. Scheer MGW, Stollman TH, Boerman OC, Verrijp K, Sweep FCGJ, Leenders WPJ, Ruers TJM, Oyen WJG (2008) Imaging liver metastases of colorectal cancer patients with radiolabelled bevacizumab: lack of correlation with VEGF-A expression. Eur J Cancer 44(13): 1835-1840

48. Schulz S, Pauli SU, Schulz S, Händel M, Dietzmann K, Firsching R, Höllt V (2000) Immunohistochemical determination of five somatostatin receptors in meningioma reveals frequent overexpression of somatostatin receptor subtype sst2A. Clin Cancer Res 6(5): $1865-1874$

49. Shahbazi-Gahrouei D (2009) Novel MR imaging contrast agents for cancer detection. J Res Med Sci 14(3):141-147

50. Simpson D (1957) The recurrence of intracranial meningiomas after surgical treatment. J Neurol Neurosurg Psychiatry 20(1):22-39

51. Tang H, Gong Y, Mao Y et al (2012) CD133-positive cells might be responsible for efficient proliferation of human meningioma cells. Int J Mol Sci 13(5):6424-6439

52. Ullrich M, Bergmann R, Peitzsch M et al (2016) Multimodal somatostatin receptor theranostics using $[(64) \mathrm{Cu}] \mathrm{Cu}-/[(177) \mathrm{Lu}] \mathrm{Lu}-$ DOTA-(Tyr(3))octreotate and AN-238 in a mouse pheochromocytoma model. Theranostics 6(5):650-665

53. Van Dam GM, Themelis G, Crane LMA et al (2011) Intraoperative tumor-specific fluorescence imaging in ovarian cancer by folate receptor- $\alpha$ targeting: first in-human results. Nat Med 17(10): $1315-1319$

54. Van Oosten M, Crane LMA, Bart J, van Leeuwen FW, van Dam GM (2011) Selecting potential targetable biomarkers for imaging purposes in colorectal cancer using TArget Selection Criteria (TASC): a novel target identification tool. Transl Oncol 4(2):71-82

55. Whittle IR, Smith C, Navoo P, Collie D (2004) Meningiomas. Lancet 363(9420):1535-1543

56. Yamasaki F, Yoshioka H, Hama S, Sugiyama K, Arita K, Kurisu K (2000) Recurrence of meningiomas. Cancer 89(5):1102-1110

57. Zhang RR, Schroeder AB, Grudzinski JJ, Rosenthal EL, Warram JM, Pinchuk AN, Eliceiri KW, Kuo JS, Weichert JP (2017) Beyond the margins: real-time detection of cancer using targeted fluorophores. Nat Rev Clin Oncol 14(6):347-364 